\title{
The association of obesity with eating disorders risk: online survey of a large cohort of Russian-speaking individuals seeking medical weight correction assistance
}

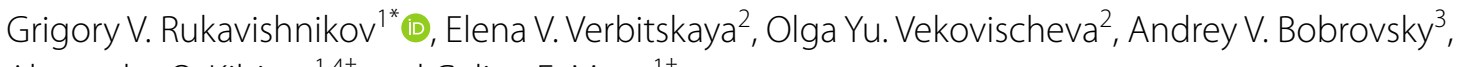
Alexander O. Kibitov ${ }^{1,4+}$ and Galina E. Mazo ${ }^{1+}$

\begin{abstract}
Background: Eating Disorders pose a serious health risk to individuals. Often, eating disorder symptoms are overlooked when assessing obesity risk. The current cross-sectional study was focused on the search of association between disordered eating behaviors evaluated by Eating Attitudes Test 26 (EAT-26) and obesity in a large cohort of Russian-speaking adults seeking online assistance with medical weight correction.
\end{abstract}

Methods: The web-based cross-sectional study evaluated the data of online Eating Attitudes Test 26 (EAT-26) completed by 13,341 registered adult visitors of weight loss clinic website. The EAT-26 provides an overall score for potential eating disorders risk, as well as scores for three subscales: Bulimia, dieting, and oral control. Additional self-reported information about sex, weight, height, and age of respondents was used for analysis. The nonparametric analysis of variance and binominal logistic regression modeling were applied to search for an association between obesity and EAT-26 total score and subscales scores. The critical level of the significance was considered as $a=0.05$.

Results: Women (94\%) had lower BMI values but higher EAT-26 total score than men, which was indicated as statistically significant by a Wilcoxon Signed-Ranks Test $(Z=-11.80, p<0.0001)$. Logistic regression for the whole cohort revealed that Bulimia subscale score was associated with higher risk of obesity $(\mathrm{OR}=1.03,95 \% \mathrm{Cl} 1.02-1.05)$ whereas higher score of EAT-26 oral control subscale was associated with decreased risk of obesity $(\mathrm{OR}=0.93,95 \% \mathrm{Cl} 0.91-$ 0.95). Separate analysis for men and women showed that in men higher obesity risk was associated with higher oral control subscale scores $(\mathrm{OR}=1.08,95 \% \mathrm{Cl} 1.06-1.11)$; while in women both dieting and bulimia subscales scores were associated with higher obesity risk $(\mathrm{OR}=1.02,95 \% \mathrm{Cl} 1.01-1.03$ and $\mathrm{OR}=1.03,95 \% \mathrm{Cl} 1.02-1.05$, respectively). Older age was associated with obesity risk for both women and men.

Conclusions: In a large cohort of individuals seeking medical weight correction assistance, the risk of obesity was associated with the higher EAT-26 scores, age, and sex. Moreover, different eating disorder risk profiles were associated with obesity in men and women. Higher oral control subscale score was associated with decreased risk of obesity in

\footnotetext{
*Correspondence: grigory_v_r@mail.ru

${ }^{\dagger}$ Alexander O. Kibitov and Galina E. Mazo have contributed equally to this work

'Department of Translational Psychiatry, V.M. Bekhterev National Medical

Research Center for Psychiatry and Neurology, 3 Bekhterev Street, Saint-Petersburg, Russia 192019

Full list of author information is available at the end of the article
} permits use, sharing, adaptation, distribution and reproduction in any medium or format, as long as you give appropriate credit to the original author(s) and the source, provide a link to the Creative Commons licence, and indicate if changes were made. The images or other third party material in this article are included in the article's Creative Commons licence, unless indicated otherwise in a credit line to the material. If material is not included in the article's Creative Commons licence and your intended use is not permitted by statutory regulation or exceeds the permitted use, you will need to obtain permission directly from the copyright holder. To view a copy of this licence, visit http://creativecommons.org/licenses/by/4.0/. The Creative Commons Public Domain Dedication waiver (http://creativecommons.org/publicdomain/zero/1.0/) applies to the data made available in this article, unless otherwise stated in a credit line to the data. 
women, but with higher risk in men. Older age was a shared obesity risk factor for both sexes. Therefore, the use of EAT-26 would facilitate individual diagnostic assessment for specific eating disorders in different sub-cohorts. Further assessment of separate EAT-26 subscales may be important to predict sex-/age-specific risks of obesity that implies their study in the future.

Plain English summary: Obesity is a significanthealth problem. Different factors (e.g. social, biological, and behavioral) areimportant for their successful treatment. Abnormal eating behaviors may be oneof the most likely predictors of increased body weight. This study aims todetermine whether there is a significant association between obesity and scoreson the eating behavior questionnaire-Eating Attitudes Test-26 (EAT-26)-in alarge cohort of adults seeking medical weight correction assistance at a privateweight loss clinic web-site. According to the study results, the associationwas shown for the male sex, older age, and higher Bulimia scores as measured onthe EAT-26. Moreover, different EAT-26 scales were associated with obesityrisks in women and men subgroups, while older age was a shared risk factor forobesity in both sexes. The findings may suggest sex-/age-specific diagnosticapproach and treatment strategies for individuals with obesity.

Keywords: Obesity, Abnormal eating behaviors, EAT-26, BMI, Online survey

\section{Background}

Overweight and obesity are among the most significant health problem in the world that increase risks of various chronic diseases such as cardiovascular pathology, metabolic disorders, gastrointestinal dysfunction, and musculoskeletal pathology [1, 2]. According to recent epidemiological data, up to $39 \%$ (about 1.9 billion) of the world's adult population is overweight, and 13\% (about 650 million) are suffering from obesity [1]. Obesity is a complex disease of multifaceted origin, including physiological, socioeconomic, biological, and behavioral factors [3-5]. Moreover, different types of disordered eating behavior patterns (binge eating, emotional eating, external eating, responding to food craving) are often associated with increased weight [6-8].

The self-reported Eating Attitude Test 26 (EAT-26) was chosen as one of the most reliable, common, and simple questionnaires to detect eating disorders risks in the human population [9-12]. The EAT-26 questionnaire has been used in Russia and in countries of the Commonwealth of Independent States (CIS) since the early 2000s $[9,13]$. According to the recommendations of the Belarus Ministry of Health, the EAT-26 can be used with the intention to screen for eating disorders in different cohorts $[9,13]$. However, numerous studies searching the association between eating disorders and obesity are focused on cohorts of limited age, such as adolescents or students, and the results remain understudied and controversial [14-19].

The individuals seeking medical weight correction assistance could be a fairly representative cohort to study the relationship between obesity and EAT-26 scores, as the treatment-seeking individuals are likely to be more aware of increased BMI and can report specific eating behaviors patterns. At the same time perception of self-weight in such individuals could be very variable and occasionally reflect conditions without the need for treatment [20]. Thus, it also seems relevant to assess the impact of sex and age on the association of weight and disordered eating behavior patterns in such a cohort. Moreover, previous findings showed that in treatmentseeking individuals with exceed BMI weight gain and loss were often associated with discorded eating behaviors, especially binge eating [21]. Because of that despite receiving proper treatment such patients could rapidly regain weight to even greater scores than initial ones, contributing to increased morbidity and mortality [21].

Therefore, further research is needed to identify the association between obesity and the occurrence of disordered eating behaviors, as well as to check whether they occur in individuals seeking medical weight correction assistance.

Our study aimed to determine whether there is a significant association between obesity and possible disordered eating behaviors measured with Eating Attitudes Test-26 in a large sample of individuals seeking medical weight correction assistance.

\section{Methods \\ Participants}

The online Eating Attitudes Test-26 (EAT-26) survey data has been collected between 2013 and 2018 from the adult Russian-speaking, medical weight correction seeking visitors of a private weight loss clinic website (https://docto rbormental.ru/).

The inclusion criteria were physical age (from 18 to 65 years), Russian Federation or CIS country citizenship, the ability to read, write and understand Russian, and signed consent to provide personal data for research purposes. Respondents were excluded from the analysis if they were outside the specified age range; had incomplete data (age, weight, height, CIS); 
or rejected the visitor's agreement. Additional selfreported information about sex, weight, height, and age of respondents was used for analysis. Survey completion took no more than $20 \mathrm{~min}$.

Data collection was secured on the clinic site. The data records contained 45,439 entries. However, 32,098 entries that did not meet the inclusion criteria $(17,164$ hid age/sex/weight/height info; 14,350 participants skipped items of the EAT; 120 put incorrect data (e.g. age $=8$, and weight $=800 \mathrm{~kg}$ ); 286 had age at $<18$ or $>65)$, as well as duplicate entries $(n=3)$ were found), were excluded from the study. Also 78 participants $(0.3 \%$ of the cohort) with BMI values below normal $(\mathrm{BMI}<18.5)$ were excluded from statistical modeling due to their dissonance to the pre-specified study focus. Thus, the information from 13,341 respondents who lived in 8 administrative regions of the Russian Federation or at 5 CIS countries was analyzed.

The study was approved by the Institutional Review Board (IRB). Research principles of the human study were consistent with the general ethical principles of the World Medical Association Declaration of Helsinki (2013).

\section{Online survey}

The online version of the Eating Attitude Test 26 (EAT26) was used to detect risks of disordered eating behaviors. A cutoff score of 20 (inclusive) is considered to indicate the risk of an eating disorder and, therefore, the reason to recommend contact with a mental health specialist [10].

The Kettle's method $\left(\mathrm{kg} / \mathrm{m}^{2}\right)$ was used to calculate BMI automatically [1]. The EAT-26 was divided categorically on three subscales: dieting (score range 0-39), Bulimia (score range $0-18$ ) and oral control (score range 0-18). Total EAT-26 scores $\geq 20$, suggested a risk of eating disorders [10].

Preliminary statistical analysis revealed that EAT-26 scores and age had a non-linear relationship (Fig. 1), which led to the decision to convert age from a continuous measure into groups, for the purpose of statistical modeling. The categories chosen for age were: (1) 18-24 years old, (2) 25-44 years old, (3) 45-59 years old, and (4) above 60 years old in accordance with the international age classification criteria [22].

Similarly, for the analysis purposes, BMI was also converted from a continuous to a categorical variable, divided by WHO classification [1] into 2 categories: normal and Overweight with $18.5 \leq \mathrm{BMI}<30$ versus Obesity

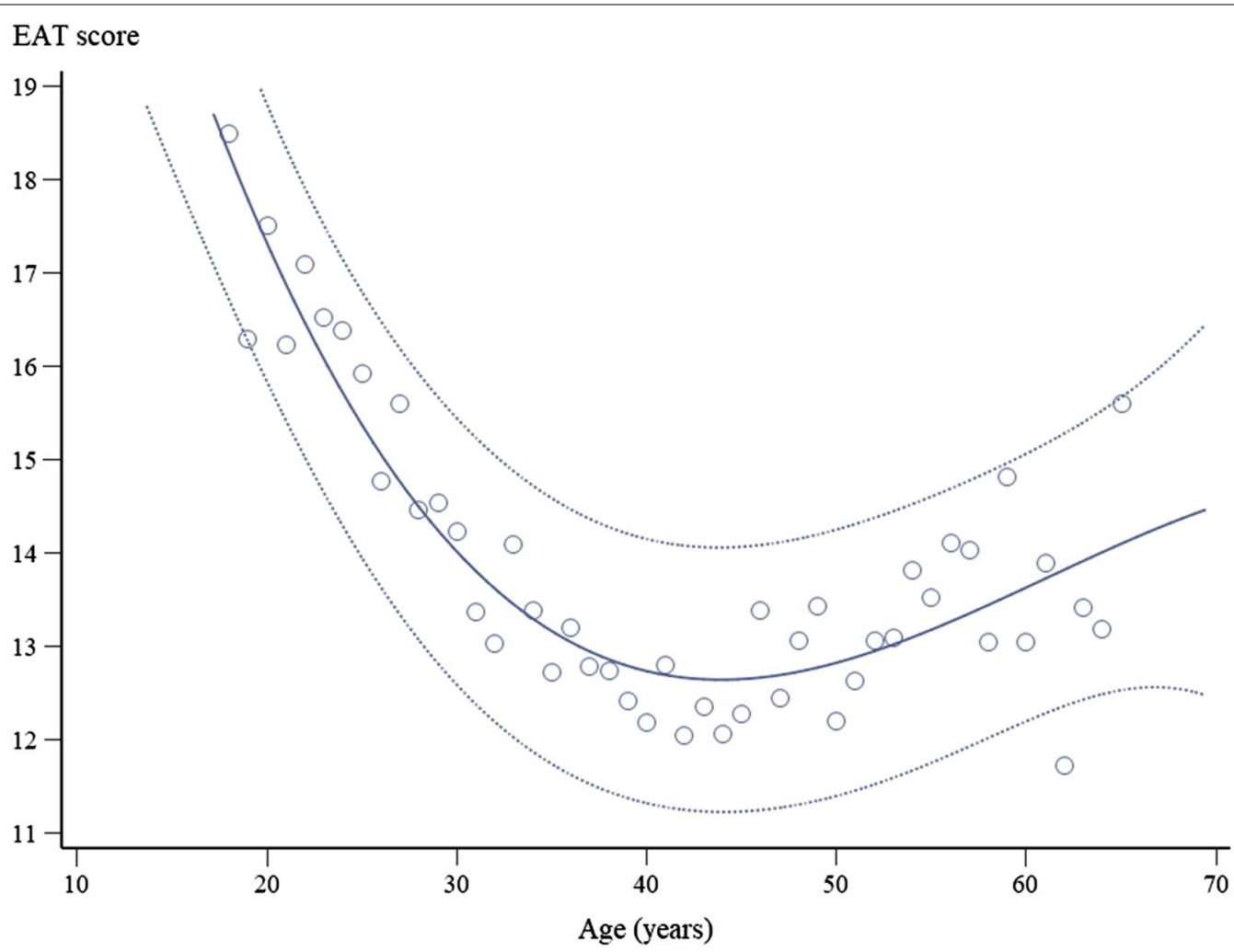

Fig. 1 Scatter-plot of correlation between EAT-26 score and age 
with $\mathrm{BMI} \geq 30$ (including Obesity I, Obesity II and Obesity III).

\section{Statistical analysis}

Statistical analysis was performed using the statistical software package SAS 9.4. First, the distribution of independent variables was calculated as mean and standard deviation [Mean (SD)] or median and quartiles (Me) [Q1; Q3]. The critical level of the significance (null hypothesis rejection) was considered $\alpha=0.05$. The nonparametric analysis of variance and binominal logistic regression modeling were applied to search for an association between BMI and EAT-26 subscales scores. Finally, BMI, EAT-26 total score, and EAT26 subscale scores were used as quantitative scales or categorical variables depending on the statistical test. The categorical variables such as age (4 groups), sex (2 groups), BMI (2 groups), and EAT-26 (2 groups) were presented as frequency and percentage (\%) and were analyzed by cross-tab method with Pearson Chi-Square test $\left(x^{2}\right)$ or with Fisher exact test to observe differences. The EAT-26 score was analyzed using (1) Wilcoxon Two-Sample Test (also known as Wilcoxon SignedRanks Test) to compare sex differences and (2) nonparametric analysis of variance (ANOVA; Kruskal-Wallis test) to estimate the influence of factors such as age, sex, and BMI. Bonferroni multiple comparisons test was used if the null hypothesis was rejected by $\mathrm{p}<0.05$ for post hoc comparisons. The analyses were repeated for the EAT-26 subscales Dieting, Bulimia, and Oral control. Several binomial logistic regressions were constructed to predict obesity (BMI $\geq 30$ ) (yes/no) in the cohort by sex, age and EAT-26 subscale scores and their interactions. One regression model was built for the whole cohort and two separate regressions modelled for the female and the male subgroups separately.

\section{Results}

Age, sex and BMI characteristics of the cohort

Cohort composition for men and women by age, BMI and EAT-26 scores is presented in Table 1 . The women differed from men in all measurements except for the oral control subscale of the EAT-26 (see column Wilcoxon Two-Sample Test).

Cohort comparisons of BMI categories obesity and no obesity by age, BMI and EAT-26 scores (Table 2) indicated the BMI categories were similar by EAT-26 total score and EAT-26 dieting subscale score (see column Wilcoxon Two-Sample Test).

Table 1 Cohort composition for men and women by age, BMI and EAT-26 scores

\begin{tabular}{|c|c|c|c|c|c|c|c|c|c|c|c|c|c|c|c|c|}
\hline & \multicolumn{10}{|c|}{ Gender } & \multirow{2}{*}{\multicolumn{5}{|c|}{ All $(N=13,341,100 \%)$}} & \multirow[t]{3}{*}{ Wilcoxon two-sample test } \\
\hline & \multicolumn{5}{|c|}{ Women ( $\mathrm{N}=12,628,94.7 \%)$} & \multicolumn{5}{|c|}{ Men $(\mathrm{N}=713,5.3 \%)$} & & & & & & \\
\hline & Mean & SD & Median & Q1 & Q3 & Mean & SD & Median & Q1 & Q3 & Mean & SD & Median & Q1 & Q3 & \\
\hline Age (years) & 37.7 & 9.96 & 36 & 30 & 44 & 39.2 & 10.06 & 38 & 32 & 46 & 37.7 & 9.97 & 37 & 30 & 44 & $Z=4.13 ; p<0.0001$ \\
\hline BMI & 31.9 & 6.89 & 31.0 & 26.8 & 35.8 & 36.0 & 7.59 & 34.9 & 30.8 & 39.9 & 32.1 & 6.99 & 31.2 & 27 & 36 & $Z=14.87 ; p<0.0001$ \\
\hline EAT score & 13.8 & 8.57 & 12 & 7 & 19 & 10.3 & 8.32 & 9 & 4 & 14 & 13.58 & 8.6 & 12 & 7 & 19 & $Z=-11.80 ; p<0.0001$ \\
\hline Dieting & 10.3 & 6.06 & 10 & 6 & 14 & 7.9 & 5.85 & 7 & 3 & 12 & 10.2 & 6.08 & 10 & 5 & 14 & $Z=-10.99 ; p<0.0001$ \\
\hline Bulimia & 2.1 & 2.75 & 1 & 0 & 3 & 1.2 & 2.14 & 0 & 0 & 2 & 2.0 & 2.73 & 1 & 0 & 3 & $Z=-9.98 ; p<0.0001$ \\
\hline Oral control & 1.3 & 1.88 & 1 & 0 & 2 & 1.3 & 2.07 & 0 & 0 & 2 & 1.3 & 1.89 & 1 & 0 & 2 & $Z=-1.07 ; p=0.2848$ \\
\hline
\end{tabular}

${ }^{a} \mathrm{~N}$-absolute number of the subjects, \%—percentage of total cohort, SD—standard deviation, Q1 and Q3—-the first (25\%) and the third quartile

Table 2 Cohort composition for obesity and no obesity categories by age, BMI and EAT-26 scores

\begin{tabular}{|c|c|c|c|c|c|c|c|c|c|c|c|c|c|}
\hline & \multicolumn{12}{|l|}{ BMI } & \multirow[t]{3}{*}{ Wilcoxon two-sample test } \\
\hline & \multicolumn{6}{|c|}{ Obesity (BMI $\geq 30$ ) } & \multicolumn{6}{|c|}{ No obesity (BMI < 30) } & \\
\hline & $\mathrm{N}$ & Mean & SD & Median & Q1 & Q3 & $\mathrm{N}$ & Mean & SD & Median & Q1 & Q3 & \\
\hline Age & 7687 & 39.64 & 10.16 & 38 & 32 & 47 & 5654 & 35.17 & 9.1 & 34 & 29 & 41 & $Z=-24.84 ; p<0.0001$ \\
\hline EAT score & 7687 & 13.42 & 8.26 & 12 & 7 & 18 & 5654 & 13.79 & 9.03 & 12 & 7 & 19 & $Z=0.64 ; p=0.521$ \\
\hline Dieting & 7687 & 10.06 & 5.92 & 10 & 6 & 14 & 5654 & 10.3 & 6.28 & 10 & 5 & 14 & $Z=1.35 ; p=0.1774$ \\
\hline Bulimia & 7687 & 2.06 & 2.67 & 1 & 0 & 3 & 5654 & 2 & 2.81 & 1 & 0 & 3 & $Z=-3.84 ; p=0.0001$ \\
\hline Oral control & 7687 & 1.19 & 1.82 & 0 & 0 & 2 & 5654 & 1.41 & 1.97 & 1 & 0 & 2 & $Z=7.80 ; p<0.0001$ \\
\hline
\end{tabular}




\section{Influences associated with BMI}

\section{Analysis of variance}

Analysis of variance for BMI by age, sex, and EAT-26 score revealed that age and sex factors only were associated independently with BMI $\left(\mathrm{F}_{3,13325}=29.99, \mathrm{p}<0.001\right.$ and $\mathrm{F}_{1,13325}=40.89, \mathrm{p}<0.001$, respectively). BMI was higher in men compared to women. Men of the youngest age category (18-24 years) had lower BMI than all other categories; 25-34 years men had lower BMI than $45-59$ years and over 60 years men. $45-59$ years and over 60 years categories of men showed similar BMI.

\section{Binomial logistic regression}

Binominal logistic regressions were constructed to get how the age, sex, and EAT-26 score and their interactions may predict obesity (BMI $>=30$ ) outcome (yes/no).

The regression constructed for the whole cohort (Table 3) revealed that the higher EAT-26 Bulimia subscale score was associated with a higher risk of obesity $(\mathrm{OR}=1.03,95 \%$ CI 1.02-1.05) whereas a higher score of EAT-26 Oral control subscale was associated with decreased risk of obesity $(\mathrm{OR}=0.93,95 \%$ CI 0.91-0.95). The risk of obesity was higher in men $(\mathrm{OR}=3.13,95 \% \mathrm{CI} 2.59-3.79)$ and in participants older than 24 years old: $25-44$ years $(\mathrm{OR}=1.95,95 \% \mathrm{CI}$
1.7-2.23); 45-59 years (OR $=4.15,95 \%$ CI 3.56-4.82); over 60 years $(\mathrm{OR}=7.96,95 \% \mathrm{CI} 5.71-11.09)$. The classification power of the model was $62 \%(\mathrm{AUC}=0.623)$.

The regression constructed for the women-only revealed that the higher EAT-26 Bulimia and dieting subscale scores were associated with a higher risk of obesity $(\mathrm{OR}=1.03,95 \% \mathrm{CI} 1.02-1.05$ and $\mathrm{OR}=1.02$, 95\% CI 1.01-1.03, respectively) whereas a higher score of EAT-26 oral control subscale was associated with decreased risk of obesity $(\mathrm{OR}=0.93,95 \% \mathrm{CI}$ $0.92-0.95)$. In addition, the risk of obesity was higher in women of 45-59 years and over 60 years age categories compared to the youngest age category $(\mathrm{OR}=4.87$, 95\% CI 4.18-5.67 and OR=3.96, 95\% CI 3.04-5.16, respectively). The classification power of the model was $61 \%$ (AUC $=0.607$ ). The regression constructed for the men only revealed that the higher EAT-26 oral control subscale score was, on the contrary, associated with higher risk of obesity $(\mathrm{OR}=1.08,95 \% \mathrm{CI} 1.06-1.11)$. The risk of obesity increased in men of 25-44 years and 44-59 years age categories as compared with the men of the youngest age category $(\mathrm{OR}=5.75,95 \% \mathrm{CI}$ $3.10-10.68$ and $\mathrm{OR}=11.44,95 \%$ CI 5.38-24.44, respectively). The classification power of the model was $58 \%$ $(\mathrm{AUC}=0.575)$.

Table 3 Modeling effects of sex, age and EAT-26 scores on the BMI (obesity/no obesity) outcome (binominal logistic regression)

\begin{tabular}{|c|c|c|c|c|c|c|c|c|}
\hline \multirow[t]{3}{*}{ Parameter } & \multicolumn{5}{|c|}{ Analysis of maximum likelihood estimates } & \multicolumn{3}{|c|}{ Odds ratio estimates } \\
\hline & \multirow[t]{2}{*}{ DF } & \multirow[t]{2}{*}{ Estimate } & \multirow[t]{2}{*}{ Standard error } & \multirow[t]{2}{*}{ Wald chi-square } & \multirow[t]{2}{*}{ Pr $>$ ChiSq } & \multirow[t]{2}{*}{ Point estimate } & \multicolumn{2}{|c|}{$\begin{array}{l}95 \% \text { wald } \\
\text { confidence } \\
\text { limits }\end{array}$} \\
\hline & & & & & & & Min- & Max \\
\hline \multicolumn{9}{|l|}{ Cohort } \\
\hline Bulimia & 1 & 0.034 & 0.007 & 24.729 & $<.0001$ & 1.03 & 1.02 & 1.05 \\
\hline Oral control & 1 & -0.073 & 0.010 & 56.210 & $<.0001$ & 0.93 & 0.91 & 0.95 \\
\hline Men versus women & 1 & 0.571 & 0.048 & 139.219 & $<.0001$ & 3.13 & 2.59 & 3.79 \\
\hline Age $25-44$ versus $18-24$ & 1 & -0.374 & 0.046 & 64.806 & $<.0001$ & 1.95 & 1.70 & 2.23 \\
\hline Age $45-59$ versus $18-24$ & 1 & 0.381 & 0.053 & 52.424 & $<.0001$ & 4.15 & 3.56 & 4.82 \\
\hline Age $>60$ versus $18-24$ & 1 & 1.034 & 0.119 & 75.645 & $<.0001$ & 7.96 & 5.71 & 11.09 \\
\hline \multicolumn{9}{|l|}{ Women } \\
\hline Dieting & 1 & 0.020 & 0.003 & 40.099 & $<.0001$ & 1.02 & 1.01 & 1.03 \\
\hline Bulimia & 1 & 0.030 & 0.008 & 15.461 & $<.0001$ & 1.03 & 1.02 & 1.05 \\
\hline Oral control & 1 & -0.069 & 0.011 & 42.945 & $<.0001$ & 0.93 & 0.92 & 0.95 \\
\hline Age $25-44$ versus $18-24$ & 1 & -0.064 & 0.030 & 4.435 & 0.0352 & 2.46 & 2.16 & 2.81 \\
\hline Age $45-59$ versus $18-24$ & 1 & 0.617 & 0.043 & 209.672 & $<.0001$ & 4.87 & 4.18 & 5.67 \\
\hline Age $>60$ versus $18-24$ & 1 & 0.412 & 0.083 & 24.421 & $<.0001$ & 3.96 & 3.04 & 5.16 \\
\hline \multicolumn{9}{|l|}{ Men } \\
\hline Oral control & 1 & 0.080 & 0.013 & 37.186 & $<.0001$ & 1.08 & 1.06 & 1.11 \\
\hline Age $25-44$ versus $18-24$ & 1 & 0.511 & 0.127 & 16.106 & $<.0001$ & 5.75 & 3.10 & 10.68 \\
\hline Age $45-59$ versus $18-24$ & 1 & 1.198 & 0.205 & 34.150 & $<.0001$ & 11.44 & 5.38 & 24.34 \\
\hline Age $>60$ versus $18-24$ & 1 & -0.469 & 0.302 & 2.422 & 0.1196 & 2.16 & 0.78 & 5.98 \\
\hline
\end{tabular}




\section{Discussion}

The association between BMI and EAT-26 score was performed on the cohort of Russian-speaking individuals who voluntarily sought online medical assistance for weight correction. Around 58\% of our respondents had obesity, while only $30 \%$ of the general Russian population in 2012-2014 was reportedly classified overweight or having obesity [23]. To the best of our knowledge, there were no previous studies of obesity prevalence in weight correction-seeking individuals in a Russian population. However, our study showed a lower-than-average BMI index compared to other studies of individuals with obesity seeking weight loss treatment [24].

The fact that BMI was higher in men than in women, which contradicts the findings for the general Russian population [23], may suggest that men begin to seek medical assistance with a weight problem when the problem becomes severe. Also, similar findings of sex influence were found for treatment-seeking individuals with exceeding BMI, where men had higher BMI's and were older than women [24]. The high ratio of females to males in our cohort is common for other studies of treatmentseeking individuals with exceeding BMI [20, 21, 24, 25].

The higher EAT-26 total score in women may indicate that the eating disorders are more common for the women $[12,26]$. The sex differences of higher BMI and higher EAT-26 total score in women were demonstrated in Jamaican adolescents [19]. In contrast, the research in adolescents of urban secondary schools in Sarawak, Malaysia, shows opposite findings [16]. In the current study, BMI was higher in men while EAT-26 total score was higher in women.

The dividing for sex approach revealed an association between BMI was dependent on the ages of both women and men: the youngest showed lower weight (see Table 3). Thus, we assume the association between $\mathrm{BMI}$ and eating risk may be specific to men and women. On the other hand, previous results of disordered eating behaviors research in treatment-seeking individuals with obesity showed variable and even inconsistent results, from significantly higher to very low prevalence of disordered eating patterns than the general population $[20,21$, $24,25]$. Perhaps, the different methodological approaches to identify disordered eating behaviors (diagnostic interview vs. self-reported questioner) might be a reason for such contradictions.

Another interesting finding of our study was different association of separate EAT-26 subscales with obesity risk in men and women. Thus, higher oral control subscale score was associated with decreased risk of obesity in woman, but higher risk in men. One of the possible explanations for that could be increased weight gain after the period of restrictions and control in men [21].
Considering the significant association of different EAT sub-scales in males and females, subscales of EAT-26 may be important in themselves to predict sex-specific risks of weight gain that implies their study in the future.

\section{Limitations}

The study has several limitations. First, the study utilized a cross-sectional design, which means we could not track any changes in the relationship between eating disorder risk and changes in weight over time. Second, the data were received from self-selected people seeking weight loss assistance online (with a proportion of them either underweight or normal weight) limiting the ability to extrapolate results to the general population. Moreover, the usage of the online questioner with free access can lead to some issues. Beyond self-reporting errors (such as with height and weight), the quality of the data received was lowered and, therefore, severely limited the number of respondents included in the analysis. Also, the age was collected continuously and then transformed into categories, resulting in the loss of power (although not substantial considering the large sample size). Finally, the number of women in our study was much higher than men, which could also affect our results' generalizability.

\section{Conclusions}

The study of the association between obesity and eating disorder risk (EAT-26 scores) in the adult Russian-speaking individuals seeking medical assistance for weight correction showed that the older males who scored higher on the Bulimia EAT-26 subscale were at potentially higher risk of developing obesity. Moreover, different eating disorder risk profiles were associated with obesity in men and women. Higher oral control subscale score was associated with decreased risk of obesity in women, but with higher risk in men. Older age was a shared obesity risk factor for both sexes. Therefore, the use of EAT-26 would facilitate individual diagnostic assessment for specific eating disorders in different sub-cohorts. Further assessment of separate EAT-26 subscales may be important to predict sex-/age-specific risks of obesity that implies their study in the future.

\section{Abbreviations \\ BMI: Body mass index; Cl: Confidence interval; CIS: Commonwealth of inde- pendent states; EAT-26: Eating attitudes test-26; OR: Odds ratio; WHO: World} Health Organization.

\section{Acknowledgements}

We would like to thank the team of the clinic "Dr. Bormental" for the database creation and the collaborators of V.M. Bekhterev National Medical Research Center for supporting the study. Special thanks to Dr. Cynthia Bulik for the constructive advices on improving our manuscript and Dr. Olga Baboshina for the language review. 


\section{Authors' contributions}

$G M, A K, A B$ designed the study and wrote the protocol. $A B$ organized the data collection. EV and OV conducted the statistical analysis. GR conducted literature searches, provided summaries of previous research studies and evaluated the analysis data. EV and OV provided tables and graphic materials. GR wrote the first draft of the manuscript. All authors contributed to and have approved the final manuscript.

\section{Funding}

The authors received no specific funding for this work.

\section{Availability of data and materials}

The datasets used and/or analyzed during the current study are available from the corresponding author on reasonable request.

\section{Declarations}

Ethics approval and consent to participate

The study was approved by the local ethic committee (IRB) of V.M. Bekhterev National Research Center for Psychiatry and Neurology (\#EC-I-17/21).

\section{Consent for publication}

Not applicable.

\section{Competing interests}

The authors declare that they have no competing interests.

\section{Author details}

${ }^{1}$ Department of Translational Psychiatry, V.M. Bekhterev National Medical Research Center for Psychiatry and Neurology, 3 Bekhterev Street, Saint-Petersburg, Russia 192019. ${ }^{2}$ I.P. Pavlov First Saint-Petersburg State Medical University, 6-8 Lev Tolstoy St., Saint-Petersburg, Russia 197022. ${ }^{3}$ Saint-Petersburg State University, 7-9 University Enb., Saint-Petersburg, Russia 199034. ${ }^{4}$ V.P. Serbsky National Medical Research Centre on Psychiatry and Addictions, 23 Kropotkinskiy Lane, Moscow, Russia 119034.

Received: 8 April 2021 Accepted: 4 August 2021 Published online: 14 August 2021

\section{References}

1. Obesity and overweight. (n.d.). Retrieved 6 Jan 2021, from http://www. who.int/mediacentre/factsheets/fs311/en/

2. Chooi YC, Ding C, Magkos F. The epidemiology of obesity. Metabolism. 2019:92:6-10. https://doi.org/10.1016/j.metabol.2018.09.005.

3. Conway B, Rene A. Obesity as a disease: no lightweight matter. Obes Rev. 2004;5(3):145-51. https://doi.org/10.1111/j.1467-789X.2004.00144.x.

4. Incledon E, Wake M, Hay M. Psychological predictors of adiposity: systematic review of longitudinal studies. Int J Pediatr Obes. 2011;6(2-2):e1-11. https://doi.org/10.3109/17477166.2010.549491.

5. Schlesinger S, Neuenschwander M, Schwedhelm C, Hoffmann G, Bechthold A, Boeing H, Schwingshackl L. Food groups and risk of overweight, obesity, and weight gain: a systematic review and dose-response metaanalysis of prospective studies. Adv Nutr. 2019;10(2):205-18. https://doi. org/10.1093/advances/nmy092.

6. O'Reilly GA, Cook L, Spruijt-Metz D, Black DS. Mindfulness-based interventions for obesity-related eating behaviours: a literature review. Obes Rev. 2014;15(6):453-61. https://doi.org/10.1111/obr.12156.

7. Hayes JF, Fitzsimmons-Craft EE, Karam AM, Jakubiak J, Brown ML, Wilfley DE. Disordered eating attitudes and behaviors in youth with overweight and obesity: implications for treatment. Curr Obes Rep. 2018;7(3):235-46. https://doi.org/10.1007/s13679-018-0316-9.

8. McCuen-Wurst C, Ruggieri M, Allison KC. Disordered eating and obesity: associations between binge-eating disorder, night-eating syndrome, and weight-related comorbidities. Ann N Y Acad Sci. 2018;1411(1):96-105. https://doi.org/10.1111/nyas.13467.
9. Meshkova TA, Nikolaeva NO. Eating attitude test (EAT-26) on a sample of students in Moscow. Psychiatry. 2017;1(73):34-41.

10. Garner DM, Olmsted MP, Bohr Y, Garfinkel PE. The eating attitudes test: psychometric features and clinical correlates. Psychol Med. 1982:12(4):871-8. https://doi.org/10.1017/s0033291700049163.

11. Dotti A, Lazzari R. Validation and reliability of the Italian EAT-26. Eat Weight Disord. 1998;3(4):188-94. https://doi.org/10.1007/BF03340009.

12. Siervo M, Boschi V, Papa A, Bellini O, Falconi C. Application of the SCOFF, eating attitude test 26 (EAT 26) and eating inventory (TFEQ) Questionnaires in young women seeking diet-therapy. Eat Weight Disord. 2005;10(2):76-82. https://doi.org/10.1007/BF03327528.

13. Prof. Skugarevsky OA. Methods of disordered eating behaviors diagnostics. (2005) Retrieved 28 June 2021: from: https://www.bsmu.by/downl oads/vrachu/instrukcii/28-0205.pdf

14. Lynch W, Eppers K, Sherrodd J. Eating attitudes of Native American and white female adolescents: a comparison of BMl- and age-matched groups. Ethn Health. 2004;9(3):253-66. https://doi.org/10.1080/13557 85042000250094

15. Neumark-Sztainer D, Wall M, Larson NI, Eisenberg ME, Loth K. Dieting and disordered eating behaviors from adolescence to young adulthood: findings from a 10-year longitudinal study. J Am Diet Assoc. 2011;111(7):1004-11. https://doi.org/10.1016/j.jada.2011.04.012.

16. Cheah WL, Hazmi H, Chang CT. Disordered eating and body image issues and their associated factors among adolescents in urban secondary schools in Sarawak, Malaysia. Int J Adolesc Med Health. 2017. https://doi. org/10.1515/ijamh-2015-0044.

17. Nagata JM, Garber AK, Tabler JL, Murray SB, Bibbins-Domingo K. Prevalence and correlates of disordered eating behaviors among young adults with overweight or obesity. J Gen Intern Med. 2018;33(8):1337-43. https://doi.org/10.1007/s11606-018-4465-z.

18. Al-Kloub Ml, Al-Khawaldeh OA, Al-Bashtawy M, Batiha AM, Al-Haliq M. Disordered eating in Jordanian adolescents. Int J Nurs Pract. 2019;25(1):112694. https://doi.org/10.1111/ijn.12694.

19. Harrison AN, James Bateman CCB, Younger-Coleman NOM, et al. Disordered eating behaviours and attitudes among adolescents in a middleincome country. Eat Weight Disord. 2020;25(6):1727-37. https://doi.org/ 10.1007/s40519-019-00814-5.

20. Akindele $\mathrm{MO}$, Phillips J, Igumbor $\mathrm{E}$, Useh U. Body weight misperception and dissatisfaction among overweight and obese adult Nigerians. JMIR Public Health Surveill. 2017;3(3):e56. https://doi.org/10.2196/publicheal th.7047.

21. Marchesini G, Cuzzolaro M, Mannucci E, et al. Weight cycling in treatment-seeking obese persons: data from the QUOVADIS study. Int J Obes Relat Metab Disord. 2004;28(11):1456-62. https://doi.org/10.1038/ sj.ijo.0802741.

22. of International Economic D, Affairs S. Provisional guidelines on standard international age classifications. United Nations New York; 1982.

23. Kontsevaya A, Shalnova S, Deev A, et al. Overweight and obesity in the Russian population: prevalence in adults and association with socioeconomic parameters and cardiovascular risk factors. Obes Facts. 2019;12(1):103-14. https://doi.org/10.1159/000493885.

24. Ernst B, Wilms B, Thurnheer M, Schultes B. Eating behaviour in treatmentseeking obese subjects - influence of sex and BMI classes. Appetite. 2015;95:96-100. https://doi.org/10.1016/j.appet.2015.06.019.

25. Vamado PJ, Williamson DA, Bentz BG, et al. Prevalence of binge eating disorder in obese adults seeking weight loss treatment. Eat Weight Disord. 1997;2(3):117-24. https://doi.org/10.1007/BF03339961.

26. Rivas $T$, Bersabé $R$, Jiménez $M$, Berrocal $C$. The eating attitudes test (EAT26): reliability and validity in Spanish female samples. Span J Psychol. 2010;13(2):1044-56. https://doi.org/10.1017/s1138741600002687.

\section{Publisher's Note}

Springer Nature remains neutral with regard to jurisdictional claims in published maps and institutional affiliations. 